\title{
As Representações da Dança: uma Análise Sociológica
}

\author{
Josiane Medina* \\ Marcos Ruiz** \\ Danielle B. L. de Almeida*** \\ Andréa Yamaguchi**** \\ Wanderley Marchi $\mathrm{Jr}^{\text {****** }}$
}

\begin{abstract}
Resumo: A dança é uma forma de manifestação social que representa aspectos característicos de uma sociedade, podendo ser compreendida por diferentes aspectos de análise. O objetivo deste estudo foi analisar a visão de alunos prévestibulandos sobre a dança. Os dados foram analisados descritivamente, fundamentando-se na abordagem sociológica de Pierre Bourdieu. Foi possível verificar que a dança é um capital cultural estabelecido por uma série de condições sociais de estruturas dominantes. Assim, diferentes características podem ser identificadas nas danças do homem, da mulher, da criança, do velho, do pobre e na do rico.
\end{abstract}

Palavras-chave: Dança. Percepção social. Bourdieu.

\section{INTRODUÇÃo}

Os primeiros movimentos apresentados pela criança, desde o seu nascimento, mesmo por meio dos movimentos reflexos, demonstram um tipo utilitário de manifestação que, de alguma forma, representam as necessidades de sobrevivência do indivíduo, seja pela busca de alimentação, locomoção ou outra forma de manifestação corporal qualquer.

\footnotetext{
* Mestre em Educação Física. Docente na Universidade Estadual de Londrina. Centro de Educação Física e Esporte. Londrina-PR, Brasil. E-mail: josi medina@pop.com.br

"Mestre em Educação Física pela Universidade Federal do Paraná. Departamento de Educação Física. Curitiba-PR, Brasil. E-mail: mruiz@ hotmail.com

"** Especialista em Dança - Corpo contemporâneo pela Faculdade de Artes do Paraná. E-mail: daniberbel@ hotmail.com

Mestre em Educação Física pela Universidade Federal do Paraná. Departamento de Educação Física. Curitiba-PR, Brasil. E-mail: andreafpb @ hotmail.com

**** Doutor. Docente na Universidade Federal do Paraná. Departamentos de Educação Física e Ciências sociais. Curitiba-PR, Brasil. E-mail: marchijr@ufpr.br
} 
Ao longo do crescimento e desenvolvimento, as habilidades motoras básicas como sentar, engatinhar, rolar, saltar são conquistadas, constituindo-se no suporte para aquisição de movimentos mais elaborados e no campo para afloração das ações de criação e representação dos movimentos mais refinados. Assim, as diversas ações corporais do indivíduo adquirem, ao longo do tempo, cunho voluntário, pelas quais irão demonstrar seus sentimentos, desejos e emoções.

Esses gestos voluntários apresentam características adquiridas de determinada convivência entre as pessoas e o meio ambiente e podem apresentar-se como a identidade de determinado grupo.

A dança, portanto, pode ser entendida como uma forma de movimento elaborado, que fornece elementos ou representações da cultura dos povos, sendo considerada uma manifestação dos hábitos e costumes de uma determinada sociedade.

Durante décadas, a humanidade estabeleceu um contato direto entre sua dança e as representações na sociedade, traduzindo necessidades, anseios e transformações, como também a forma de manifestação das suas crenças, suas religiosidades e tradições. O homem, como ser social, utiliza-se dessa forma de expressão para representar uma cultura, porém, esse processo não necessariamente inclui, em sua reflexão, mecanismos integrantes necessários para a formação das instituições sociais nas quais está inserido.

Quando Bourdieu (2003), estabelece o conceito de habitus, considerando que os sistemas de relações são subjetivos, ele afirma que não se deve estabelecer relação enquanto somatória de indivíduos biológicos, mas como sistema de disposições no qual as práticas objetivas podem ser baseadas na impessoalidade, refletindo a diversidade na homogeneidade.

\begin{abstract}
A lógica pela qual os agentes optam por esta ou aquela prática não se pode entender a não ser que suas disposições em torno do esporte, que são em si mesmas uma dimensão de uma particular relação com o corpo, sejam reinseridas na unidade do sistema de disposições, o habitus, que é a base geradora de estilos de vida. (BOURDIEU, 1993, p. 74)
\end{abstract}

Mevimento, Porto Alegre, v. 14, n. 02, p. 99-113, maio/agosto de 2008. 
Assim, a maneira como o indivíduo assume pensamentos e reflexões acerca de determinadas ações e posturas advém do conhecimento e da formação de uma história ligada à influência familiar e à educação. Estas, desempenham papéis centrais no conjunto de conhecimentos associados ao desenvolvimento do habitus e aquisição de novas posturas.

\title{
2 A DANÇA NA HISTÓRIA: ALGUNS ASPECTOS
}

O movimento corporal executado pelos povos primitivos era a principal forma de comunicação e comunhão entre eles. A dança utilizada não servia apenas como movimentação corporal, mas como a ligação entre o homem e os seus deuses. Dançavam para a colheita, para a fertilização, para a diversão, para agradecer e, principalmente, para comunicação e entendimento entre os membros daquela sociedade.

\begin{abstract}
Antes de ascender a um palco para fazer-se dança artística teatral, o movimento dançado foi primeiro transbordamento emocional, manifestação desordenada dos temores, afetos, iras e recusas, sem outra organização particular, possivelmente, que uma apaixonada atração pelo ritmo [...] passou a ser sucessivamente conjuro mágico, rito, cerimônia, celebração popular e por fim simples diversão (OSSONA, 1988, p. 42).
\end{abstract}

Movimentos repetitivos, gestos incansáveis, o corpo levado ao êxtase, marcam essa fase da trajetória que a dança percorreu ao longo de toda sua existência. No princípio, não existia qualquer preocupação com a performance e o rendimento do corpo para atingir elevados níveis de qualidade técnica. No entanto, sua presença no cotidiano das pessoas era muito próxima, pois não separava o momento em que se dançava dos demais fatos vividos. Tudo era muito orgânico e natural no dançar e viver em sociedade.

No decorrer da história, a humanidade passou a viver em grupos isolados. Surgiram, então, diversas sociedades e cada uma passou a ter as suas próprias danças desempenhando uma função de identificação. (BOURCIER, 1987).

Movimento, Porto Alegre, v. 14, n. 02, p. 99-113, maio/agosto de 2008. 
As danças foram aprimorando-se, as pessoas dançavam cada vez mais e toda movimentação foi transformando-se em diversão e entretenimento. O homem passou a sentir prazer em realizar e assistir dança. As pessoas que dançavam passaram a se dedicar, a "ensaiar" e transmitir suas danças para outras, o que, mais tarde, denominou-se "platéia". As famílias que possuíam fortuna formavam as primeiras platéias e a dança era executada em bailes públicos (OSSONA, 1988).

$\mathrm{Na}$ corte francesa surge o primeiro bailarino de que se tem notícia: Luís XIV. Com ele também surgem os professores e escolas de dança que contribuíram para a transformação da dança, passando do sentido de comunhão com deuses para entretenimento e profissionalização:

\begin{abstract}
Também, pela primeira vez, surge o profissionalismo, com dançarinos profissionais e mestres de dança. É fato importante: até então, a dança era uma expressão corporal de forma relativamente livre. A partir desse momento, toma-se consciência das possibilidades de expressão estética do corpo humano, da utilidade das regras para explorá-lo. Além disso, o profissionalismo caminha, sem dúvida, no sentido de uma elevação do nível técnico [...] os professores de dança não pertencem a um nível social baixo: fazem parte do meio imediato dos príncipes [...] (BOURCIER, 1987, p. 64).
\end{abstract}

Com o estabelecimento de regras e normas, os passos que chamamos hoje de ballet clássico foi codificado. Pierre de Beauchamps foi o responsável pelas primeiras codificações da dança e, com a criação da primeira escola de dança, o ballet passou a ser profissão, transformando corpos de bailarinos em verdadeiras ferramentas para vinculação de uma idéia.

A partir de então, a dança exigia de seus intérpretes horas de ensaios para moldar o corpo em uma proposta pré-estabelecida. Cada vez mais buscavam ultrapassar os limites dos seus corpos, acreditando que assim atingiriam a perfeição dos movimentos e gestos.

Muitos conflitos foram criados e muitos bailarinos não permaneciam dançando por muito tempo, tornando-se impróprio seguir 
as regras existentes. Em meio a esse cenário, surge Isadora Duncan, dançarina norte-americana que propôs uma dança completamente diferente do ballet clássico acadêmico da época.

Segundo Navas e Dias (1992), Isadora procurou inspiração em movimentos da natureza. Estabeleceu uma dança livre de espartilhos, meias, sapatilhas de pontas, apresentando-se em coreografias solos, descalça e vestida em túnicas de seda (vestimentas inapropriadas para os bailarinos clássicos da época, que dançavam com meias e malhas coladas ao corpo).

Isadora contribuiu muito mais do que na simples quebra de paradigmas de movimentações corporais. Sua contribuição ajudou para estabelecer uma nova visão da movimentação que respeitasse os padrões anatômicos de cada bailarino, evitando que o tempo de vida profissional fosse diminuído por desgastes provocados por execução de movimentos repetitivos e exaustivos.

A dança, portanto, recebeu um novo conceito perante a sociedade. Dançar não é apenas atividade das classes nobres da burguesia francesa, mas também de pessoas comuns que apenas gostem de movimentar o corpo como maneira de expressão.

A dança moderna aparece com uma proposta de movimentação diferenciada das vistas até então pelos bailarinos clássicos. Surgem diversas técnicas, inúmeras escolas, mas todas explorando as regras e codificações de passos e gestos como forma de busca da estética do movimento desejado.

Com o aprimoramento das técnicas de dança moderna, outros princípios estéticos foram incorporados à dança. A busca por diversos e novos movimentos e a quebra dos padrões acadêmicos possibilitou que teóricos passassem a pensar o que se estava dançando. Rudolf Von Laban se destacou por sua contribuição com um método de análise do movimento (SANTOS, 2001).

As teorias de movimento do pesquisador, artista plástico e coreógrafo Rudolf Von Laban, desenvolvidas na Alemanha na primeira metade do século XX, poderiam ser vistas como uma terceira via de entendimento, como uma sobreposição das

Movimento, Porto Alegre, v. 14, n. 02, p. 99-113, maio/agosto de 2008. 
abordagens objetivas e subjetivas, entre as teorias e práticas de atuação (FERNANDES, 2002).

Um observador de uma pessoa em movimento fica imediatamente consciente, não apenas dos percursos e ritmos de movimento, mas também das atmosferas que os percursos carregam em si, já que as formas do movimento através do espaço são atingidas pelos sentimentos e pelas idéias. E o conteúdo dos pensamentos e emoções que temos ao nos movermos ou ao observarmos o movimento podem ser analisados tanto quanto as formas e linhas traçadas no espaço (LABAN apud FERNANDES, 2002, p. 18).

Laban permitiu aos bailarinos analisarem movimentos que antes eram apenas executados. Socialmente, a dança avançou para uma posição importante utilizada para observação e aprimoramento estético dos corpos que dançam. Dessa forma, o cenário criado por Laban colocou a dança e os bailarinos em meio a uma compreensão onde os corpos que dançam não apenas executam movimentos representados por alguém, mas pensam e analisam as possibilidades de criação a partir de um repertório de imagens e idéias construídas ao longo da vida. Porém, a visão de uma arte de elite ainda persiste na visão geral da sociedade contemporânea:

Em nossa "sociedade civilizada", se é que ainda podemos denominá-la assim, a dança, como quase tudo, passou a ser valorizada como produto comercializável, tão rapidamente elaborado quanto consumido e de fácil digestão. Grande parte dos nossos jovens dançarinos só se interessa pelo que já conhece através dos meios de comunicação de massa, pelos artifícios efêmeros que estão na moda, preferindo o aplauso imediato ao sentimento interior de realização (OSSONA, 1988, p. 09).

Dessa forma, apesar da mudança ressaltada no sentido evolucionário da dança, tem-se como um problema a compreender: como os segmentos sociais percebem esses corpos que dançam e a visão formada por elas na sociedade atual? Outra questão pertinente é: qual a visão de determinada sociedade sobre a manifestação e a

Movimento, Porto Alegre, v. 14, n. 02, p. 99-113, maio/agosto de 2008. 
análise da representação por meio de expressões e movimentações corporais?

\section{O MÉtodo}

O estudo foi conduzido em duas etapas, sendo a primeira referente a uma pesquisa bibliográfica sobre a temática em questão e, a segunda, relativa a uma pesquisa exploratória.

A pesquisa exploratória foi realizada no Colégio e Curso PréVestibular de São José dos Pinhais - PR, com a participação de 59 alunos pré-vestibulandos, sendo 30 mulheres e 29 homens, na faixa etária entre 16 a 20 anos. A amostra foi caracterizada de acordo com o nível de formação dos alunos. Responderam o questionário alunos estudantes ou recém formados do último ano do Ensino Médio. Optou-se por esse grupo porque eles encontram-se em fase de escolha do campo profissional, não estando inseridos profundamente numa área específica do conhecimento.

O questionário compreendeu questões abertas e fechadas sobre o conhecimento deste grupo sobre a dança como: os tipos de dança, profissionais de destaque, bailarinos ou envolvidos com o ensino, o papel da dança na vida social e se esta fez parte de sua formação escolar.

Os dados foram analisados descritivamente, com base em livros e artigos científicos da área, fundamentando-se na abordagem sociológica de Pierre Bourdieu.

\section{Resultados e Discussão}

Os resultados apresentados nos questionários forneceram informações que permitiram desenvolver algumas associações com pressupostos teóricos de Bourdieu.

A amostra utilizada não manifestou grande variabilidade quanto à faixa-etária, demonstrando que $61 \%$ dos alunos pré-vestibulandos

Movimento, Porto Alegre, v. 14, n. 02, p. 99-113, maio/agosto de 2008. 
participantes do estudo estavam na faixa etária de 17 anos de idade, seguido por $30,5 \%$ na faixa etária de 16 anos de idade.

Procurou-se verificar de quais estilos de dança os estudantes tinham maior conhecimento. As respostas apresentaram uma diversificação nos estilos, como: o forró, a valsa, o break, o hip hop, o street dance, axé, jazz, ballet, sendo este último mais lembrado pelos estudantes.

Fazendo uma leitura desses relatos, é possível chamar a atenção ao que Bourdieu (1996) chama de sistemas de preferências, quando o autor afirma que as características do conhecimento são pertinentes à condição social e econômica. Considerando assim, relacionamos o nível sócio-econômico dos entrevistados, inferindo que o ballet, considerado uma prática restrita à maioria da população, está presente no cotidiano desses alunos, marcando uma posição do indivíduo ou grupos no espaço dos estilos de vida.

Essa diferença, observada quanto à aproximação com determinados estilos de dança, foi gerada a partir de determinadas condições materiais de existência, em conjunto com os elementos de preferências do grupo em oposição às preferências de outros grupos, em outras posições. Isto, por sua vez, reproduz as diferenças ligadas à estrutura da distribuição dos instrumentos de apropriação, transformadas, desse modo, em distinções simbólicas (BOURDIEU, 1998).

Sobre a proximidade dos alunos pré-vestibulandos a algum profissional da área de dança, não restringindo a possibilidade de resposta somente ao professor da atividade em específico, 47,5\% dos alunos afirmaram conhecer um profissional, seja ele professor, dançarino, coreógrafo, dono de academia e pessoas que praticam dança como forma de exercício físico. Isto apresenta uma maior relação com o universo da dança, favorecendo aos mesmos a aquisição de um determinado capital cultural, em específico sobre a dança em relação aos demais.

Fazendo uma leitura desta evidência, é pertinente relacionar o que Bourdieu chama de capital social, visto que ele entende este

Mevimento, Porto Alegre, v. 14, n. 02, p. 99-113, maio/agosto de 2008. 
aspecto como uma rede durável de relações mais ou menos institucionalizadas, vinculadas a um determinado grupo que é dotado de propriedades comuns e unidos por ligações permanentes, dependendo da rede de relações e do volume de capital que possui (BOURDIEU, 1998).

Fica ainda mais evidente a distinção do capital cultural relacionado à dança, quando o foco é o gênero. As mulheres, em sua maioria $(60 \%)$, responderam positivamente ao conhecimento entre profissionais da dança, enquanto que $65,5 \%$ dos homens, diferentemente dessas, relataram não conhecer nenhum profissional da área.

Essa composição nos faz sugerir a possibilidade dos condicionamentos sociais, relacionados ao gênero, terem favorecido as mulheres na construção de um habitus, de modo geral, associando a dança à feminilidade (BOURDIEU, 1996). Estes resultados vão de encontro ao exposto por Sanderson (2001) em um estudo com adolescentes de 11 a 16 anos. Os resultados da investigação demonstraram que as mulheres têm mais atitudes positivas para o ballet do que os homens. O autor cita, ainda, a colocação de Pollard (1988), que argüi que os adolescentes homens são inseguros e pouco dispostos a estarem associados com quaisquer atividades as quais possam ser interpretadas como femininas.

Ao analisar-se a questão que investiga o conhecimento dos alunos sobre um profissional da área da dança e que tenha algum papel de destaque na sociedade, verificou-se que menos da metade dos pré-vestibulandos responderam positivamente $(42,4 \%)$. E destes, a maioria foram mulheres $(46,7 \%)$. Como a questão formulada pretendeu deixar totalmente aberto para os alunos percorrerem suas possibilidades de conhecimento em relação aos diferentes aspectos ligados à área da dança, as respostas foram múltiplas envolvendo dançarinos de grupos de axé destacados pela mídia, profissionais ligados ao ensino e ao espetáculo dos estilos de dança, além de artistas e cantores.

Por outro lado, tendo os signos, num sistema simbólico, uma função de relação com outros signos, ou seja, sendo seu valor dado pela posição que ocupam no sistema, o estilo de vida significa também 
relações de associação ou dissociação no sistema de estratificação. Logo, as formas ou estilos de consumo - por exemplo, das artes ou bens materiais - contribuem fundamentalmente para o conhecimento do significado atribuído pelos grupos às suas ações e da própria imagem social do grupo (BOURDIEU, 1998).

Um ponto interessante que nos permite avançar em algumas análises pode ser verificado com relação aos profissionais mais citados estarem ligados a estilos de dança, como: de salão, a valsa, o forró, o samba, o tango, contrariando uma possível aproximação com o ballet, estilo de dança apresentado como o mais citado.

Podemos, nesse caso, sugerir que o capital cultural de uma determinada classe social é legitimada por outra, no momento que é o estilo de dança mais reconhecido pelo grupo mas, em contradição, a realidade vivida é distante, sendo associado à rede de relacionamentos com outros estilos distintos. De acordo com Araújo (1997), adaptados a um contexto cultural, em grande parte imposto e veiculado pela indústria cultural, a atração do adolescente pela linguagem do movimento ocorre apenas no âmbito do lazer. No caso da dança, observa-se uma grande rejeição pelo aprendizado formal e acadêmico, justamente por não fazerem parte de seus cotidianos.

Assim, para analisar o processo de formação escolar destes alunos, abordou-se uma questão a respeito de disciplinas curriculares que tenham, em seu conteúdo, alguma relação com a dança. Encontrou-se $62,7 \%$ de alunos que não tiveram contato com a dança durante a sua formação escolar. Observou-se, ainda, que a maior parte das respostas (20\%) esteve vinculada à disciplina de Educação Física, seguida pela disciplina de Artes. Além disto, os tipos de dança praticados pelos alunos mais citados foram: ballet, jazz, dança do ventre e danças típicas.

Em um estudo realizado por Marcelino (2005), que verificou as causas geradoras da estrutura para a prática da dança por crianças de 9 a 12 anos, participantes de uma turma de dança de um programa de esportes, foi observado que a oferta da modalidade era uma das causas da procura. As crianças praticam por gostarem de dançar e

Movimento, Porto Alegre, v. 14, n. 02, p. 99-113, maio/agosto de 2008. 
por ser uma atividade prazerosa. Além disto, pôde-se verificar que as crianças fazem usos sociais diversos dessa prática, entretanto, não verificando claramente o que causa as disposições para a dança.

No presente trabalho, pretendeu-se verificar a experiência dos indivíduos com a prática da dança durante a sua formação escolar e se esta abordagem foi realizada no âmbito das disciplinas escolares, ou seja, como parte integrante do currículo escolar. Conforme exposto, encontrou-se que a maioria dos indivíduos não teve oportunidades de prática de dança durante a fase escolar, o que suscita outra questão referente à limitação desta prática no âmbito escolar, e se relaciona ao analisado por Marcelino, sobre a oferta do produto, que irá gerar a procura pelo consumo. Conforme Sanderson (2001), o paradoxo de altos níveis de interesse recreacional dos adolescentes na dança e a severidade limitada às oportunidades oferecidas nas escolas para a educação desta, tem recebido atenção de pesquisadores na literatura.

O que se pode ressaltar com relação às experiências dos alunos durante o seu processo de formação escolar, e que apresenta uma contribuição na aquisição de um capital cultural sobre um futuro interesse pelo consumo da dança, é a oportunidade de saber que é possível desenvolver um gosto. Portanto, há um acúmulo de capital cultural que gera um interesse de consumo em diferentes níveis sociais.

\section{Considerações Finals}

Analisando o questionário e os relatos dos alunos, foi possível constatar que existe um determinado capital cultural adquirido sobre a dança. As análises apontaram para novas reflexões em torno desse universo pois, independente do estilo de dança específico de cada grupo, todos estavam atrelados ao seu universo. Como exemplo, podemos citar a diversidade de ritmos e estilos apresentados e, também, a aproximação que grande parte dos alunos relatou ter com personalidades que se destacam no ambiente da dança.

Movimento, Porto Alegre, v. 14, n. 02, p. 99-113, maio/agosto de 2008. 
Ficou, também, evidente, que existe uma distinção em relação à proximidade com a dança, considerando o gênero. $\mathrm{O}$ que, por sua vez, identifica a possibilidade que as meninas dispõem, por meio do sistema de ensino, para adquirir o gosto pela atividade. Com isso, evidencia-se o papel da escola durante o processo de formação dos jovens na construção de um capital cultural em dança. Entretanto, a prática pedagógica desenvolvida nesse meio reforça os valores, vivenciados em toda sociedade, de que a dança é atividade direcionada ao gênero feminino.

Consideramos isso um atraso em relação à disseminação da dança enquanto prática ou consumo, o que reforça valores distorcidos pela incompreensão de elementos do universo da dança. Isso pode gerar conflitos, ao considerar a dúvida sobre a masculinidade do homem que dança um erotismo exacerbado atribuído pela mídia aos corpos seminus expostos na televisão. Fica claro, também, o reforço da distinção de classes, tendo em vista o perfil sócioeconômico dos entrevistados, com o direcionamento da aquisição do gosto pela dança, em que os estilos desenvolvidos estão mais próximos às classes consideradas privilegiadas, como o ballet e o jazz.

Vemos a dança como uma manifestação de direito dos povos, independente da cor, religião, sexo, poder sócio-econômico e outras barreiras que poderiam ser inibidoras no processo de democratização. A dança representa os símbolos e significados da maneira de viver dos grupos sociais. É como inibir ou retirar a possibilidade de uma pessoa sentir emoções, de expressar seus sentimentos. Está sendo roubada a oportunidade de homens e mulheres desfrutarem da plenitude de suas vidas, quando se lhes impedem de experimentar as diferentes sensações na dança.

O distanciamento do hábito do convívio com o universo da dança é um condicionamento que as estruturas sociais dominantes estabeleceram ao povo. Assim, existe a dança do homem, a dança da mulher, a dança da criança, a dança do velho, a dança do pobre e a dança do rico.

Acreditamos que seja possível romper alguns paradigmas sobre a dança e sua relação com a sociedade, e as instituições de ensino

Movimento, Porto Alegre, v. 14, n. 02, p. 99-113, maio/agosto de 2008. 
apresentam um papel primordial nesse percurso, no qual podem decidir em continuar perpetuando valores que não condizem mais com nossa realidade, ou acordam para trilhar novos caminhos. Certamente isso nos remete ao processo formativo dos professores que ali atuam e as condições que enfrentam na realidade escolar. Embora não tenha sido abordado no texto, sugere-se como uma continuidade de investigação, considerar a visão dos professores escolares sobre a dança, considerando-os como uma categoria profissional específica que influencia no contexto pedagógico na aquisição de valores e de uma visão sobre o papel social da dança que os jovens perpetuam na sociedade atual.

Movimento, Porto Alegre, v. 14, n. 02, p. 99-113, maio/agosto de 2008. 
Representations of dance: the social analysis

Abstract: Dance is a way of social manifestation which represents specific aspects of a society that may be understood by different aspects of analysis. The aim of this study was to analyze the view about dance of individuals who were about to get in a university. Descriptive analysis of the data was performed based on Pierre Bourdieu's social approach. It was possible to understand that dance is a cultural capital established by some social conditionings set by dominant structures to their people. So, different characteristics may be identified among the different reported ways of dance related to the man, woman, child, elderly, poor people and rich people.

Keywords: Dancing. Social Perception. Bourdieu.

\begin{abstract}
Las representaciones de la danza: una análisis sociológica

Resumen: La danza es una forma de manifestación social que representa aspectos específicos de una sociedad y se puede entender por los diferentes aspectos de análisis. El objetivo de este estudio fue analizar el conocimiento de quien estaba a punto de ingresar en una universidad sobre la danza, El analisis descriptivo de los datos se realizó basado en el acercamiento social de Pierre Bourdieu. Fue posible entender que la danza es un capital cultural establecido por un equipo social, puesto a sus personas por las estructuras dominantes. Así, pueden identificarse las características diferentes entre las maneras informadas de danza relacionadas al hombre, mujer, niño, anciano, personas pobres y la danza de personas ricas.

Palabras clave: Baile. Percepción Social. Bourdieu.
\end{abstract}

\title{
REFERÊNCIAS
}

ARAÚJO, M. V. B. A dança: laboratório multicultural relato de experiência. Revista corporis, Pernambuco - Recife, v.1, n. 1, p. 15-21, jan./dez. 1997.

BOURCIER, P. História da dança no ocidente. São Paulo: Martins Fontes, 1987.

BOURDIEU, P. Deporte y clase social. In: BROHM, J.M. Materiales de sociología del deporte. Madri: Ediciones de la Piqueta, 1993. p.57-82.

BOURDIEU, P. Razões Práticas: sobre a teoria da ação. Campinas: Papirus, 1996.

Mevimento, Porto Alegre, v. 14, n. 02, p. 99-113, maio/agosto de 2008. 
BOURDIEU, P. O poder simbólico. 2.ed. Rio de Janeiro: Bertrand Brasil, 1998.

BOURDIEU, P. Esboço de uma teoria da prática. In: ORTIZ, R. (org.). A Sociologia de Pierre Bourdieu. São Paulo: Olho d’Água, 2003.

FERNANDES, C. O corpo em movimento. São Paulo: Annablume, 2002.

MARCELINO, D. R. As práticas corporais numa abordagem sociológica: o contexto da dança. Motriz, Rio Claro, v.11, n. 1, p. 106, 2005. Supl.

NAVAS, C.; DIAS, L. Dança Moderna. São Paulo: Secretarias Municipais da Cultura, 1992.

OSSONA, P. A educação pela dança. São Paulo: Summus, 1988.

SANDERSON, P. Age and gender issues in adolescents attitudes to dance. European physical education review, Chester, v. 7, n. 2, p. 117-136, 2001.

SANTOS, E. S. A influência do balé clássico e da dança moderna nos estados de ânimo. 2001. 116 p. Dissertação (Mestrado em Motricidade Humana) - Instituto de Biociências, Universidade Estadual Paulista Júlia de Mesquita Filho, Rio Claro SP, 2001. 